\title{
The Antarctic Atmospheric Energy Budget. Part I: Climatology and Intraseasonal-to-Interannual Variability
}

\author{
Michael Previdi AND KAREN L. SMith \\ Lamont-Doherty Earth Observatory, Columbia University, Palisades, New York \\ LORENZO M. POLVANI \\ Lamont-Doherty Earth Observatory, Columbia University, Palisades, and Department of Applied Physics and \\ Applied Mathematics, and Department of Earth and Environmental Sciences, Columbia University, New York, New York
}

(Manuscript received 11 September 2012, in final form 10 January 2013)

\begin{abstract}
The authors present a new, observationally based estimate of the atmospheric energy budget for the Antarctic polar cap (the region poleward of $70^{\circ} \mathrm{S}$ ). This energy budget is constructed using state-of-the-art reanalysis products from ECMWF [the ECMWF Interim Re-Analysis (ERA-Interim)] and Clouds and the Earth's Radiant Energy System (CERES) top-of-atmosphere (TOA) radiative fluxes for the period 2001-10. The climatological mean Antarctic energy budget is characterized by an approximate balance between the TOA net outgoing radiation and the horizontal convergence of atmospheric energy transport, with the net surface energy flux and atmospheric energy storage generally being small in comparison. Variability in the energy budget on intraseasonal-to-interannual time scales bears a strong signature of the southern annular mode (SAM), with El Niño-Southern Oscillation (ENSO) having a smaller impact. The energy budget framework is shown to be a useful alternative to the SAM for interpreting surface climate variability in the Antarctic region.
\end{abstract}

\section{Introduction}

The Antarctic region serves as a key indicator and regulator of global climate change. Many signs of change in the region have already become apparent in recent decades: surface temperatures on the Antarctic Peninsula and in West Antarctica have increased rapidly (Turner et al. 2005; Mayewski et al. 2009; Steig et al. 2009), glaciers and ice shelves have retreated and in some cases collapsed (Domack et al. 2005; Mayewski et al. 2009), regional changes in sea ice have been observed (Zwally et al. 2002; Liu et al. 2004; Comiso and Nishio 2008; Turner et al. 2009), and the circumpolar westerly winds have intensified from the stratosphere down to the surface (Turner et al. 2005; Mayewski et al. 2009). Such changes in the Antarctic and Southern Ocean system can impact global climate through effects on sea level,

Corresponding author address: Dr. Michael Previdi, LamontDoherty Earth Observatory, Columbia University, 61 Route 9W, Palisades, NY 10964.

E-mail: mprevidi@ldeo.columbia.edu ocean circulation, and biogeochemical cycles. For example, mass loss from the Antarctic ice sheet is presently contributing about $0.7 \mathrm{~mm} \mathrm{yr}^{-1}$ to global sea level rise, with the magnitude of this contribution increasing with time (Rignot 2011). The volume of Antarctic Bottom Water in the World Ocean has decreased significantly during the past few decades, which is consistent with a global-scale slowdown of the bottom, southern limb of the ocean's meridional overturning circulation (Purkey and Johnson 2012). Finally, a recent weakening of the Southern Ocean sink for atmospheric $\mathrm{CO}_{2}$ has been attributed to the strengthening of the circumpolar westerly winds noted above (Le Quéré et al. 2007).

The atmosphere mediates these changes in Antarctic surface climate by strongly impacting the net surface energy flux that is available to increase surface temperatures and melt ice. Additionally, in a climatological sense, atmospheric transport accounts for the bulk of the total energy flux convergence over the southern polar cap that is required to balance the radiation deficit at the top of the atmosphere (TOA; Genthon and Krinner 1998). It follows that an understanding of the atmospheric 
energy budget is essential for understanding Antarctic and thus global climate and climate change. This paper is the first in a two-part study of the Antarctic atmospheric energy budget. We concentrate here on describing the present-day climatological mean energy budget and its variability on intraseasonal-to-interannual time scales. In Smith et al. (2013, hereafter Part II), we will focus on multidecadal trends in energy budget components and their links to stratospheric ozone changes and increases in well-mixed greenhouse gases.

Several previous studies have estimated the Antarctic atmospheric energy budget relying to different degrees on observations, reanalyses, and climate models (Nakamura and Oort 1988, hereafter NO88; Genthon and Krinner 1998; Okada and Yamanouchi 2002; van de Berg et al. 2007; Cullather and Bosilovich 2012, hereafter CB12). Here, we construct the energy budget using satellite observations from the Clouds and the Earth's Radiant Energy System (CERES; Wielicki et al. 1996) and data from the European Centre for Medium-Range Weather Forecasts (ECMWF) Interim Re-Analysis (ERA-Interim; Dee et al. 2011). Our work thus updates earlier estimates of the Antarctic energy budget using the latest generation satellite and reanalysis products.

CB12 also employed contemporary reanalysis data to derive the energy budget, focusing mainly on the Modern-Era Retrospective Analysis for Research and Applications (MERRA), but additionally evaluating the ERA-Interim and Climate Forecast System Reanalysis (CFSR). They found that ERA-Interim and CFSR have a more realistic annual net surface energy flux over the Antarctic ice sheet than MERRA, because of better surface parameterizations in the former in regions of permanent land ice. ERA-Interim has also been found to generally outperform other contemporary global reanalyses in depicting variability in Antarctic precipitation (Bromwich et al. 2011), mean sea level pressure, and 500-hPa geopotential height (Bracegirdle and Marshall 2012). Aside from incorporating the latest satellite and reanalysis data, the present study also differs from earlier work by devoting considerably more time to understanding the causes of intraseasonal-to-interannual variability in the Antarctic energy budget. This sets the stage for the second part of our study, because energy budget variability on these time scales is largely controlled by the same physical mechanisms [e.g., changes in the southern annular mode (SAM)] that contribute to decadal-scale changes (Part II).

The remainder of this paper is organized as follows. Section 2 discusses the datasets that are employed in the present study and their known biases. It also describes our methodology for constructing the Antarctic atmospheric energy budget. The climatological mean energy budget is presented in section 3 . In section 4 , we assess variability in energy budget components on intraseasonalto-interannual time scales, concentrating primarily on relationships to the SAM and El Niño-Southern Oscillation (ENSO). Links between the energy budget and Antarctic surface temperature variability are also discussed. Finally, a summary and conclusions are given in section 5 .

\section{Data and methods}

Following, for example, NO88 and Trenberth (1997), the energy budget of an atmospheric column extending from the surface (SFC) to TOA can be written as

$$
\frac{\partial E}{\partial t}=F_{\mathrm{TOA}: \mathrm{NET}}+F_{\mathrm{SFC}: \mathrm{NET}}+F_{\mathrm{WALL}}
$$

where $\partial E / \partial t$ is the energy storage, $F_{\mathrm{TOA}: \mathrm{NET}}$ is the TOA net radiative energy flux, $F_{\mathrm{SFC}: \mathrm{NET}}$ is the SFC net energy flux, and $F_{\text {WALL }}$ is the vertically integrated horizontal energy flux convergence. The energy storage term can be expanded as

$$
\frac{\partial E}{\partial t}=\frac{\partial}{\partial t} \frac{1}{g} \int_{0}^{p_{S F C}}\left(c_{p} T+k+L q+\Phi_{\mathrm{SFC}}\right) d p
$$

where $g$ is the gravitational acceleration, $p$ is pressure, $c_{p}$ is the specific heat of air at constant pressure, $T$ is absolute temperature, $k$ is the kinetic energy, $L$ is the latent heat of vaporization, $q$ is specific humidity, and $\Phi_{\mathrm{SFC}}$ is the surface geopotential. Similarly, we can expand the terms on the right-hand side of Eq. (1) as follows:

$$
\begin{aligned}
F_{\mathrm{TOA}: \mathrm{NET}} & =F_{\mathrm{TOA}: \mathrm{SW}}+F_{\mathrm{TOA}: \mathrm{LW}} \\
F_{\mathrm{SFC}: \mathrm{NET}} & =F_{\mathrm{SFC}: \mathrm{SW}}+F_{\mathrm{SFC}: \mathrm{LW}}+F_{\mathrm{SFC}: \mathrm{LH}+\mathrm{SH}}, \quad \text { and } \\
F_{\mathrm{WALL}} & =-\nabla \cdot \frac{1}{g} \int_{0}^{p_{\mathrm{SFC}}}\left(c_{p} T+k+L q+\Phi\right) \mathbf{v} d p \\
& =F_{T}+F_{k}+F_{q}+F_{\Phi}
\end{aligned}
$$
and

Equation (3) states that the net TOA radiative flux is the sum of the net shortwave (SW) and the longwave (LW) fluxes. The net SFC energy flux [Eq. (4)] also includes SW and LW radiative components and additionally a nonradiative component associated with the turbulent exchange of latent heat (LH) and sensible heat (SH) between the surface and atmosphere. Equation (5) states that the total atmospheric energy flux convergence $F_{\mathrm{WALL}}$ is the sum of the convergence of the internal, 


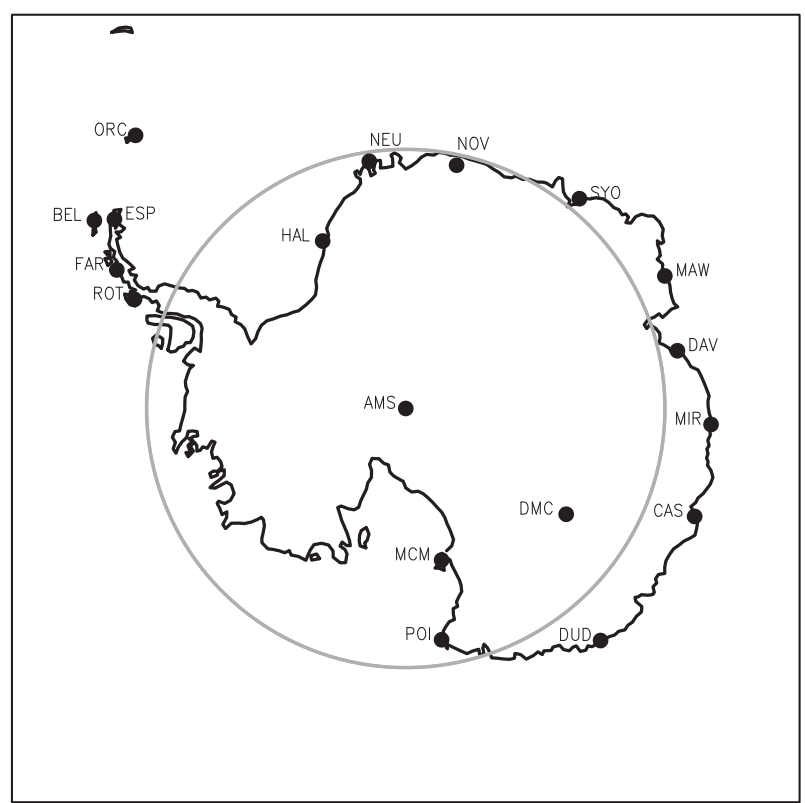

FIG. 1. Antarctica and the Southern Ocean: Energy budget components in the present study are averaged over $70^{\circ}-90^{\circ} \mathrm{S}$ (i.e., the region enclosed within the gray circle). Filled circles mark the locations of the following weather stations from which surface air temperature observations were acquired: Amundsen Scott (AMS), Bellingshausen (BEL), Casey (CAS), Davis (DAV), Dome C II (DMC), Dumont d'Urville (DUD), Esperanza (ESP), Faraday/ Vernadsky (FAR), Halley (HAL), Mawson (MAW), McMurdo (MCM), Mirny (MIR), Neumayer (NEU), Novolazarevskaya (NOV), Orcadas (ORC), Possession Island (POI), Rothera (ROT), and Syowa (SYO).

kinetic, latent, and potential energy fluxes $\left(F_{T}, F_{k}, F_{q}\right.$, and $F_{\Phi}$, respectively), with $\mathbf{v}$ being the horizontal wind vector. In the results that follow, we present areaaveraged values of all energy budget terms over the Antarctic polar cap $\left(70^{\circ}-90^{\circ} \mathrm{S}\right.$; see Fig. 1). Terms are defined to be positive when they contribute to a gain of energy for the atmospheric column. Thus, downward fluxes at the TOA, upward fluxes at the SFC, and horizontal energy flux convergence are all positive.

We construct the climatological mean Antarctic energy budget for the period 2001-10, which is the first full $10 \mathrm{yr}$ of CERES satellite measurements. Monthly CERES TOA fluxes from the Energy Balanced and Filled (EBAF) dataset were obtained on a $1^{\circ} \times 1^{\circ}$ grid from the National Aeronautics and Space Administration (NASA) Langley Research Center Atmospheric Science Data Center. To produce the EBAF data, CERES TOA SW and LW fluxes were adjusted such that the global mean net TOA flux averaged over several years is equal to the estimated present-day change in heat storage in the earth system (Loeb et al. 2009). This procedure thus eliminates the unrealistically large global mean TOA flux that exists in the unadjusted CERES data (Trenberth et al. 2009).

Surface energy fluxes and atmospheric energy storage are from ERA-Interim. While ERA-Interim generally performs better than its predecessor [the 40-yr ECMWF Re-Analysis (ERA-40)] in depicting the global energy budget (Berrisford et al. 2011), several biases remain. For example, the meridional gradient of the TOA net radiation is too small in ERA-Interim relative to CERES, a result of too little net radiative input in the tropics and too much input in the extratropics, particularly over the Southern Ocean. These ERA-Interim biases are qualitatively similar to biases reported by Trenberth and Fasullo (2010) in previous generation reanalyses and climate models, a problem that was attributed to systematic deficiencies in simulated cloud cover (which would also impact surface fluxes). Despite these limitations, state-of-the-art reanalyses such as ERA-Interim, as well as satellite data, continue to be the best available tools for estimating the energy budget on large spatial scales.

We obtained monthly ERA-Interim surface energy fluxes from ECMWF on a $1^{\circ} \times 1^{\circ}$ grid. These fluxes were accumulated from 12-h forecasts initialized by four-dimensional variational (4DVAR) data assimilation. Atmospheric energy storage was calculated from the ERA-Interim vertically integrated internal, kinetic, latent, and potential energy tendencies [see Eq. (2)]. Finally, the horizontal energy flux convergence $F_{\mathrm{WALL}}$ was computed as a residual in the energy budget (e.g., Porter et al. 2010).

Additional data were also utilized in the present study, for comparison purposes and for assessing intraseasonalto-interannual variability. ERA-Interim surface energy fluxes were compared with those from the National Centers for Environmental Prediction-National Center for Atmospheric Research (NCEP-NCAR) reanalysis (NRA; Kalnay et al. 1996). Surface radiative fluxes derived from CERES were also acquired for the period 2001-05. These fluxes were parameterized based on the measured TOA radiation. As an alternative to computing the horizontal energy flux convergence over the polar cap as a residual, we additionally performed a direct calculation of this quantity using ERA-Interim vertically integrated northward energy fluxes. The ERAInterim vertically integrated fluxes were mass adjusted by subtracting a barotropic correction term that minimizes the mass budget residual (Trenberth 1991; see also http://www.cgd.ucar.edu/cas/catalog/newbudgets). We show in the next section that the two methods of computing $F_{\mathrm{WALL}}$ agree quite well. In section 4 , we use the direct calculation of $F_{\mathrm{WALL}}$ to assess variability related to the SAM and ENSO, both for the 2001-10 period 
TABLE 1. The climatological mean Antarctic atmospheric energy budget $\left(\mathrm{W} \mathrm{m}^{-2}\right)$ for 2001-10. TOA radiative fluxes are based on CERES satellite measurements, surface energy fluxes and $\partial E / \partial t$ are from ERA-Interim, and $F_{\text {WALL }}$ is estimated as a residual. Positive values signify a gain of energy for the atmospheric column.

\begin{tabular}{|c|c|c|c|c|c|c|c|c|c|}
\hline & $\partial E / \partial t$ & $F_{\text {TOA:SW }}$ & $F_{\mathrm{TOA}: \mathrm{LW}}$ & $F_{\text {TOA:NET }}$ & $F_{\text {SFC:SW }}$ & $F_{\mathrm{SFC}: \mathrm{LW}}$ & $F_{\mathrm{SFC}: \mathrm{LH}+\mathrm{SH}}$ & $F_{\text {SFC:NET }}$ & $F_{\mathrm{WALL}}$ \\
\hline Jan & 10 & 169 & -199 & -30 & -98 & 69 & 6 & -23 & 63 \\
\hline Feb & -7 & 105 & -185 & -80 & -62 & 58 & 0 & -4 & 77 \\
\hline Mar & -13 & 40 & -169 & -129 & -21 & 44 & -10 & 13 & 103 \\
\hline Apr & -15 & 6 & -156 & -150 & -3 & 38 & -19 & 16 & 119 \\
\hline May & -10 & 0 & -148 & -148 & 0 & 38 & -24 & 14 & 124 \\
\hline Jun & -10 & 0 & -144 & -144 & 0 & 39 & -25 & 14 & 120 \\
\hline Jul & -9 & 0 & -138 & -138 & 0 & 40 & -26 & 14 & 115 \\
\hline Aug & -4 & 2 & -137 & -135 & -1 & 40 & -26 & 13 & 118 \\
\hline Sep & 4 & 20 & -145 & -125 & -10 & 42 & -23 & 9 & 120 \\
\hline Oct & 12 & 68 & -160 & -92 & -36 & 53 & -13 & 4 & 100 \\
\hline Nov & 9 & 136 & -181 & -45 & -72 & 66 & 0 & -6 & 60 \\
\hline Dec & 21 & 184 & -198 & -14 & -105 & 75 & 9 & -21 & 56 \\
\hline Annual & -1 & 61 & -163 & -102 & -34 & 50 & -13 & 3 & 98 \\
\hline
\end{tabular}

and for the longer period of ERA-Interim beginning in 1979. A monthly station-based SAM index (Marshall 2003) was obtained from the British Antarctic Survey. For ENSO, we used the Niño-3.4 index or average sea surface temperature (SST) anomaly over the region $120^{\circ}-170^{\circ} \mathrm{W}$ and $5^{\circ} \mathrm{N}-5^{\circ} \mathrm{S}$, based on the Kaplan Extended SST dataset, version 2 (Kaplan et al. 1998). The Niño-3.4 index was obtained from the International Research Institute for Climate and Society (IRI)/Lamont-Doherty Earth Observatory (LDEO) Climate Data Library at Columbia University. Finally, in order to investigate the relationship between variability in the atmospheric energy budget and Antarctic surface climate, we acquired surface air temperature (SAT) observations during 2001-10 from 18 Antarctic weather stations (see Fig. 1). These observations were made available as part of the Reference Antarctic Data for Environmental Research (READER) project (Turner et al. 2004).

\section{Climatological mean energy budget}

Individual components of the climatological mean Antarctic energy budget are shown in Table 1 for each month of the year and for the annual mean. In most months and in the annual average, the first-order balance is between the TOA net radiation $F_{\text {TOA:NET }}$ and the horizontal energy flux convergence $F_{\mathrm{WALL}}$, with the net surface energy flux and energy storage being small in comparison. This confirms the findings of earlier studies (NO88; Genthon and Krinner 1998; CB12). The $F_{\text {TOA:NET }}$ is negative throughout the year, indicating a net loss of energy at the TOA, which tends to be compensated for by horizontal energy flux convergence over the polar cap (positive $F_{\mathrm{WALL}}$ ). The $F_{\mathrm{TOA} \text { NET }}$ displays a strong seasonal cycle that is driven by the large changes in incoming SW radiation. The $F_{\mathrm{TOA}: \mathrm{Sw}}$ peaks at $184 \mathrm{~W} \mathrm{~m}^{-2}$ in December and then declines steadily to zero by May. While not as pronounced, $F_{\mathrm{TOA}}$ LW also shows a seasonal dependence, with the largest LW energy losses occurring during summer [December-February (DJF)], when atmospheric and surface temperatures are at a maximum. In accord with the seasonal variation in $F_{\mathrm{TOA}: \mathrm{NET}}, F_{\mathrm{WALL}}$ increases from its summertime minimum to a broad maximum of $115-125 \mathrm{~W} \mathrm{~m}^{-2}$ during April-September.

Surface energy fluxes and atmospheric energy storage also vary significantly with the annual cycle (Table 1 ). The energy storage is positive as the atmosphere warms up from spring into summer and negative as it cools down from fall into winter. Averaged over the course of a year, we expect $\partial E / \partial t$ to be close to zero, and this is indeed the case. At the surface, the SW and LW fluxes vary seasonally in a similar manner and for the same reasons as their TOA counterparts. The nonradiative component of the surface energy flux $F_{\mathrm{SFC}: \mathrm{LH}+\mathrm{SH}}$ is negative during most of the year and is positive only for a brief time in December and January. The seasonal variation in $F_{\mathrm{SFC}: \mathrm{LH}+\mathrm{SH}}$ is due primarily to changes in the surface SH flux rather than the LH flux (not shown). During the polar night when SW radiation is absent, the Antarctic surface cools efficiently through LW emission. This leads to the development of a near-surface inversion over the ice sheet (e.g., Connolley 1996) and consequently a downward-directed SH flux from the atmosphere to the surface, thus explaining the negative values of $F_{\mathrm{SFC}: \mathrm{LH}+\mathrm{SH}}$. With the return of solar heating in the springtime, the inversion weakens and $F_{\mathrm{SFC}: \mathrm{LH}+\mathrm{SH}}$ increases. The net surface energy flux is relatively small in magnitude throughout the year because of cancellation between its individual components. During OctoberMarch, there is significant cancellation between the negative $F_{\mathrm{SFC}: \mathrm{SW}}$ and positive $F_{\mathrm{SFC}: \mathrm{LW}}$, while during 


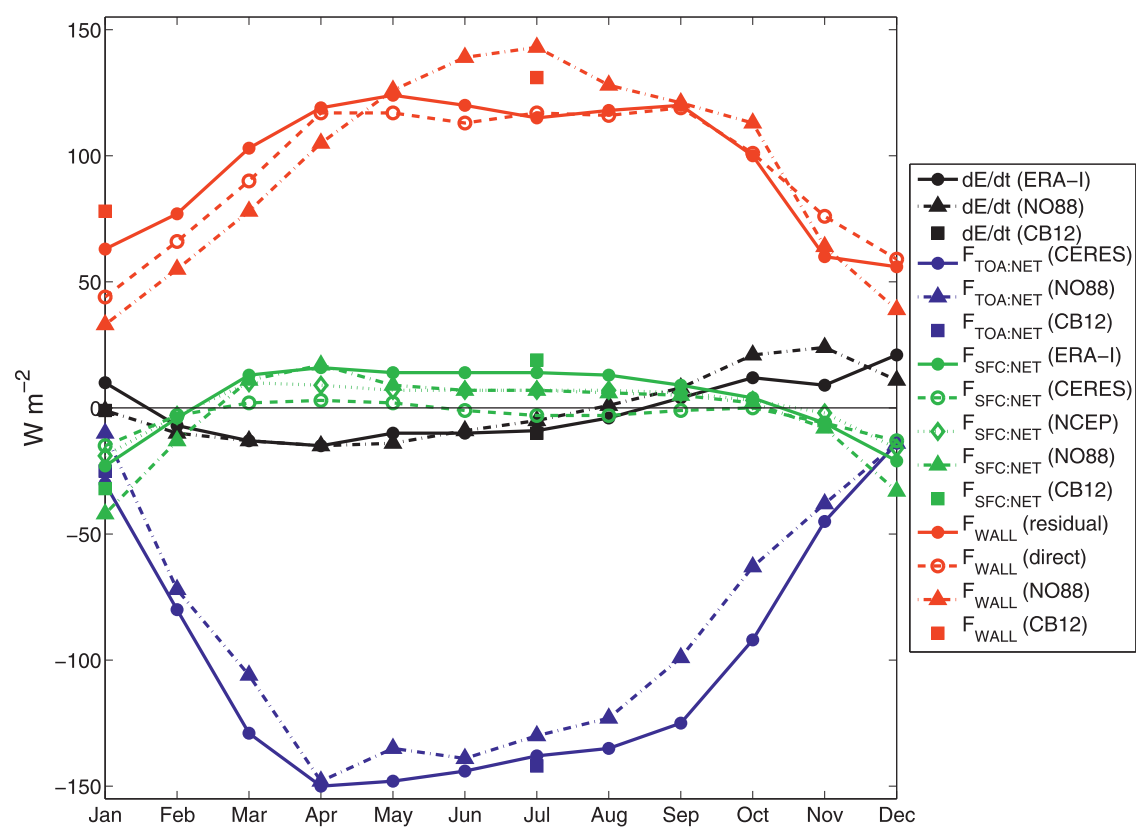

FIG. 2. Climatological mean energy budget components: solid lines correspond to the estimates given in Table $1 ; F_{\mathrm{SFC}: \mathrm{NET}}$ (CERES) is the sum of CERES surface radiative fluxes and ERA-Interim surface nonradiative fluxes; $F_{\text {SFC:NET }}(\mathrm{NCEP})$ is the net surface energy flux from the NCEP-NCAR reanalysis; $F_{\text {WALL }}$ (residual) is the horizontal energy flux convergence calculated as a residual in the energy budget, using TOA fluxes from CERES and surface energy fluxes and $\partial E / \partial t$ from ERA-Interim (see Table 1 ); and $F_{\text {WALL }}$ (direct) is the horizontal energy flux convergence calculated directly from ERA-Interim vertically integrated northward energy fluxes. CB12 estimates are for January and July only.

April-September a positive $F_{\mathrm{SFC}: \mathrm{LW}}$ is countered by a negative $F_{\mathrm{SFC}: \mathrm{LH}+\mathrm{SH}}$.

It is interesting to contrast this behavior of $F_{\mathrm{SFC}: \mathrm{NET}}$ in the Antarctic with that in the Arctic (e.g., see Porter et al. 2010). While the annual mean net surface flux in the two regions is similar, individual monthly values of $F_{\mathrm{SFC}: \mathrm{NET}}$ are much larger in magnitude in the Arctic. For example, $F_{\mathrm{SFC} \text { NET }}$ is less than $-80 \mathrm{~W} \mathrm{~m}^{-2}$ in June and July (Porter et al. 2010), a result of strong surface absorption of SW radiation. This also leads to a positive value of $F_{\text {TOA:NET }}$ during these months, another difference from the Antarctic where this quantity remains negative throughout the year (see Table 1). Differences between the Antarctic and Arctic atmospheric energy budgets are fundamentally linked to differences in the underlying surface type. In the Arctic, much of the ocean surface area is seasonally ice free, thus allowing for strong solar heating of the surface in summertime and significant exchange of $\mathrm{LH}$ and $\mathrm{SH}$ between the surface and atmosphere. Surface SW heating and turbulent energy fluxes are comparatively small in the Antarctic because of the presence of a permanent, high albedo ice sheet.

Figure 2 shows the individual terms in the Antarctic energy budget plotted as a function of month. Solid lines in the figure correspond to the estimates given in Table 1. In addition to these, alternative estimates for each energy budget component are also shown. The seasonal cycle in ERA-Interim $F_{\text {SFC:NET }}$ (solid green line) generally agrees with that found in the NRA and CERES product (dotted and dashed green lines, respectively), with the largest positive values in $F_{\mathrm{SFC}: \mathrm{NET}}$ in all three datasets occurring during March-May and the largest negative values occurring in December and January. (Note that the CERES $F_{\text {SFC:NET }}$ is the CERES surface radiative flux averaged over 2001-05 plus the ERA-Interim surface nonradiative flux.) Furthermore, all three $F_{\text {SFC:NET }}$ estimates indicate that this term is much smaller than $F_{\mathrm{TOA}: \mathrm{NET}}$ and $F_{\mathrm{WALL}}$. There are, however, differences between the $F_{\mathrm{SFC}: \mathrm{NET}}$ curves, with the two reanalyses being more similar to one another than to CERES. For example, in the latter $F_{\mathrm{SFC}: \mathrm{NET}}$ is negative during winter [June-August (JJA)], while it is positive in ERA-Interim and NRA. Because CERES surface radiative fluxes are a derived product, being parameterized based on the measured TOA fluxes, it is not clear that the CERES $F_{\mathrm{SFC}: \mathrm{NET}}$ is necessarily more realistic than $F_{\mathrm{SFC}: \mathrm{NET}}$ in ERA-Interim and NRA.

We also plot in Fig. 2 a direct calculation of $F_{\mathrm{WALL}}$ based on ERA-Interim vertically integrated and mass-adjusted 

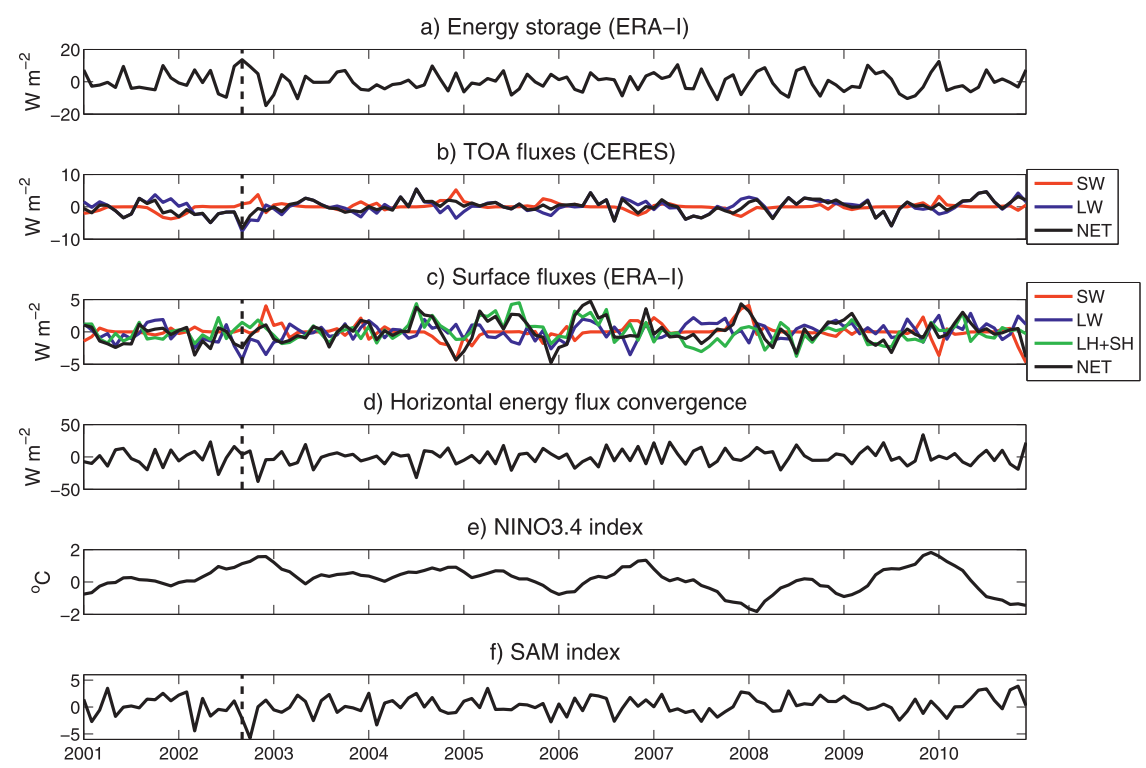

FIG. 3. (a)-(d) Energy budget components expressed as deseasonalized monthly anomalies. (e),(f) The Niño-3.4 and SAM indices (see text for details). The SAM index is in units of standard deviations. Dashed vertical lines in (a)-(d),(f) correspond to September 2002. Note the different scales on the ordinate in (a)-(f).

northward energy fluxes (dashed red line). This can be compared with the residual $F_{\text {WALL }}$ discussed earlier (solid red line). The two $F_{\mathrm{WALL}}$ estimates track each other quite well through the annual cycle, with especially good agreement during the months of July-October. In January-June, the residual $F_{\mathrm{WALL}}$ is somewhat larger than the direct calculation, while the reverse is true in November and December. In the annual mean, $F_{\text {WALL }}$ is $98 \mathrm{~W} \mathrm{~m}^{-2}\left(95 \mathrm{~W} \mathrm{~m}^{-2}\right)$ based on the residual (direct) calculation. These values lie in the middle of the range of previous estimates for the energy flux convergence over the Antarctic polar cap. Genthon and Krinner (1998) computed an $F_{\mathrm{WALL}}$ of $81 \mathrm{~W} \mathrm{~m}^{-2}$ for the period 1979-93 using data from the 15-yr ECMWF Re-Analysis. NO88 estimated a larger value of $95 \mathrm{~W} \mathrm{~m}^{-2}$ based on a 1-yr general circulation model (GCM) simulation. CB12 determined $F_{\text {WALL }}$ to be $118 \mathrm{Wm}^{-2}$ using MERRA data for 1979-2005.

Finally, Fig. 2 allows for an assessment of how our estimates of the Antarctic energy budget compare with those from previous studies. Plotted is the seasonal cycle of each energy budget component based on the results of NO88 and CB12. Note that CB12 presented tabulated estimates of the energy budget for the months of January and July only. Figure 2 indicates an overall strong agreement between our results and these other two studies, in terms of both the seasonal variability and relative magnitudes of the energy budget components. There are, however, some discernible differences. For example, $F_{\text {TOA:NET }}$ from NO88 is smaller in magnitude throughout the year than our estimate and that of CB12. The $F_{\text {WALL }}$ from NO88 is smaller than our estimate during December-April and larger during JJA. The $F_{\mathrm{WALL}}$ from CB12 is larger than our estimate in both January and July (and in the annual mean; see above). We expect that the Antarctic energy budget presented in the current study and in CB12 is generally more realistic than in NO88, given that the former studies employed a larger number of high-quality observations. It is less clear in some cases, though, whether our estimates of individual energy budget terms are more accurate than those given by CB12.

\section{Intraseasonal-to-interannual variability}

In this section, we assess variability in the Antarctic atmospheric energy budget on intraseasonal-to-interannual time scales. We determine the extent to which this variability can be explained by ENSO and the SAM, and we examine relationships with Antarctic surface temperature variability. Figures $3 a-d$ show deseasonalized (i.e., seasonal cycle removed) monthly anomalies of energy budget components for the period 2001-10. Substantial variability in the energy budget is apparent from month to month and year to year but with no discernible trends over the 10 -yr period. The amplitude of monthly anomalies tends to be larger for the energy storage and horizontal energy flux convergence (approaching $\pm 50 \mathrm{~W} \mathrm{~m}^{-2}$ in some months for $F_{\mathrm{WALL}}$ ) than for the TOA and SFC fluxes. This suggests that the latter are largely constrained 
TABLE 2. Linear correlations between energy budget components and ENSO/SAM during 2001-10 based on monthly mean data for DJF and JJA. The mean seasonal cycle was removed from the data prior to computing the correlations. Boldface values are statistically significant at the $95 \%$ confidence level.

\begin{tabular}{crccccrrrr}
\hline \hline & $\partial E / \partial t$ & $F_{\mathrm{TOA}: S W}$ & $F_{\mathrm{TOA}: \mathrm{LW}}$ & $F_{\mathrm{TOA}: \mathrm{NET}}$ & $F_{\mathrm{SFC}: \mathrm{SW}}$ & $F_{\mathrm{SFC}: \mathrm{LW}}$ & $F_{\mathrm{SFC}: \mathrm{LH}+\mathrm{SH}}$ & $F_{\mathrm{SFC}: \mathrm{NET}}$ & $F_{\mathrm{WALL}}$ \\
\hline ENSO & & & & & & & & & \\
DJF & -0.03 & 0.35 & $-\mathbf{0 . 5 4}$ & -0.28 & -0.05 & -0.06 & -0.09 & -0.12 \\
JJA & -0.04 & 0.18 & -0.36 & -0.35 & -0.13 & -0.18 & 0.07 & -0.03 \\
SAM & & & & & & & 0.28 \\
DJF & -0.19 & $-\mathbf{0 . 5 1}$ & $\mathbf{0 . 6 7}$ & 0.22 & 0.21 & 0.19 & $\mathbf{0 . 5 4}$ & $\mathbf{0 . 5 5}$ & -0.09 \\
JJA & 0.02 & -0.03 & $\mathbf{0 . 6 0}$ & $\mathbf{0 . 6 0}$ & 0.17 & -0.20 & 0.29 & 0.21 & 0.02 \\
\hline
\end{tabular}

on intraseasonal-to-interannual time scales by the presence of a permanent ice sheet. Figures $3 \mathrm{e}$ and $3 \mathrm{f}$ depict the monthly Niño-3.4 and SAM indices. In section 4a, we use these indices to assess quantitatively the relationship between ENSO/SAM and the energy budget. Note that the SAM index, defined here as the anomalous zonal mean sea level pressure difference between $40^{\circ}$ and $65^{\circ} \mathrm{S}$ (Marshall 2003), varies on shorter time scales than the Niño-3.4 index; this reflects the different time scales of the atmospheric circulation and SST.

One noteworthy feature in Fig. 3 is the energy budget response to the Southern Hemisphere major sudden stratospheric warming (SSW) in September 2002 (e.g., Orsolini et al. 2005). Positive anomalies in energy storage are consistent with higher atmospheric temperatures. Higher temperatures also explain the negative anomalies in TOA and SFC LW radiation, the largest such anomalies in the entire 10-yr record. These LW flux changes are evident in the net energy flux changes at the TOA and SFC. Negative anomalies in the LW flux at the TOA are associated with increases in the outgoing longwave radiation (OLR), whereas at the SFC they are associated with decreases in the net upward LW flux because of enhanced downward emission from the atmosphere. The September 2002 SSW was followed 1 month later by the largest negative excursion of the SAM index during the 2001-10 period (Fig. 3f). This delay is consistent with the approximate time required for stratospheric circulation anomalies to propagate down to the surface (Baldwin and Dunkerton 1999, 2001; Thompson et al. 2005). Following this, in November 2002, the largest negative $F_{\text {WALL }}$ anomaly in the record occurred (Fig. 3d). In Part II, we will discuss in greater detail the relationship between stratospheric changes, the SAM, and horizontal energy flux convergence over the polar cap.

\section{a. Links to the southern annular mode and El Niño-Southern Oscillation}

We now assess more quantitatively how the Antarctic energy budget is impacted by variability in ENSO and the SAM. Table 2 shows the linear correlations between energy budget components and the Niño-3.4 and SAM indices during 2001-10. Correlations were computed separately for DJF and JJA using deseasonalized monthly mean (rather than seasonal mean) anomalies, thus increasing the sample size. We concentrate here on statistically significant correlations ( $95 \%$ confidence) in boldface font. For ENSO, the only significant correlation is with $F_{\text {TOA:LW }}$ in DJF. The correlation is negative, indicating that OLR increases along with the Niño-3.4 index. This is consistent with Antarctic surface and tropospheric temperatures being on average higher during warm ENSO (or El Niño) events (Smith and Stearns 1993; Calvo Fernández et al. 2004). The overall lack of statistically significant correlations with ENSO in Table 2 is probably due in part to the fact that we have averaged the energy budget components over the entire Antarctic polar cap (i.e., the area between $70^{\circ}$ and $90^{\circ} \mathrm{S}$ ). ENSO is known to produce opposite-signed anomalies in surface temperature, meridional winds, cloud fraction, and precipitation in the Weddell and Ross Sea regions (Bromwich et al. 2004), suggesting that any ENSO signature in the atmospheric energy budget may not be apparent when polar cap averages are considered. It is further worth noting that the relationship between ENSO and Antarctic climate is not stable with time (Turner 2004), and thus the correlations in Table 2 may be somewhat sensitive to the particular time period used to compute them. This is especially true given the rather short length $(10 \mathrm{yr})$ of the data records examined here. Because ENSO has a time scale of about 3-7 yr (Trenberth et al. 2007), we are sampling a limited number of events, thus increasing the likelihood that atypical or outlier events will influence our results. Future work should therefore look to affirm the ENSO-energy budget correlations presented here using longer data records.

Correlations between the Antarctic energy budget and the SAM are generally stronger than for ENSO (Table 2). This is perhaps not surprising given that the SAM is the leading mode of variability of the Southern Hemisphere extratropical circulation on month-to-month time scales (Thompson and Wallace 2000). The positive phase of the SAM is characterized by negative sea level 

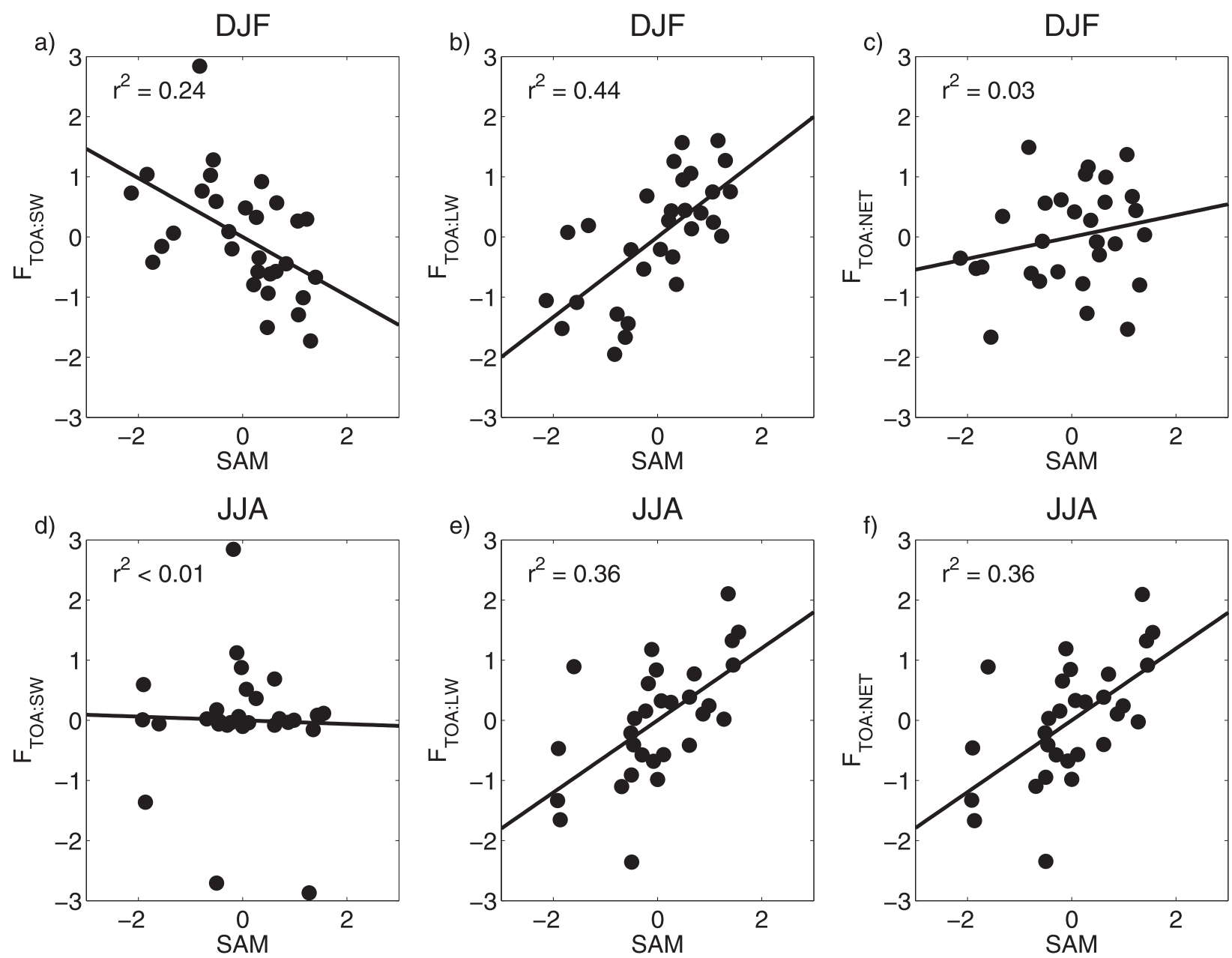

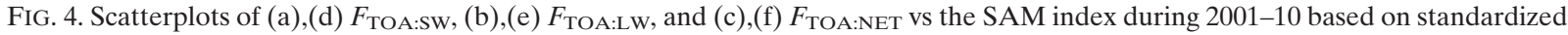
monthly mean anomalies from DJF and JJA. The mean seasonal cycle has been removed. Black lines are a least squares linear fit to the data.

pressure (SLP) anomalies over the Antarctic polar cap and positive anomalies at Southern Hemisphere midlatitudes. This pattern of SLP (or geopotential height) anomalies strengthens the meridional SLP gradient and thus intensifies the circumpolar westerly winds. The band of strongest westerly winds associated with the tropospheric jet also shifts poleward, with a related poleward shift in the storm track. Enhanced storminess at high southern latitudes drives anomalous rising motion over the polar cap, which fundamentally explains the negative tropospheric temperature anomalies in this region during the positive phase of the SAM (Thompson et al. 2003). SAT anomalies associated with the SAM are also negative over most of Antarctica, with the Antarctic Peninsula being an important exception where positive SAT anomalies occur (e.g., Thompson et al. 2011).

Table 2 indicates that there is a significant positive correlation in DJF between the SAM and the SFC turbulent energy flux, which leads to a similar correlation with the net SFC energy flux. This correlation with $F_{\mathrm{SFC}: \mathrm{LH}+\mathrm{SH}}$ is due to the effects of the SAM on the SFC SH flux, as the correlation with the SFC LH flux is not statistically significant (not shown). A positive relationship between the SAM and the SFC SH flux is indicative of an anomalous upward flux of $\mathrm{SH}$ from the surface to the atmosphere when the SAM index is positive. This anomalous SH flux is an expected response to the overall decrease in Antarctic SAT associated with the SAM that is noted above (e.g., Thompson et al. 2011).

TOA radiative fluxes also vary in concert with the SAM (Table 2 and Fig. 4). In DJF, there is a significant negative correlation between $F_{\mathrm{TOA}: \mathrm{Sw}}$ and the SAM index. This negative correlation is likely due primarily to increased cloudiness over the polar cap during the positive phase of the SAM, because the correlation between the SAM index and the clear-sky TOA SW radiation is 

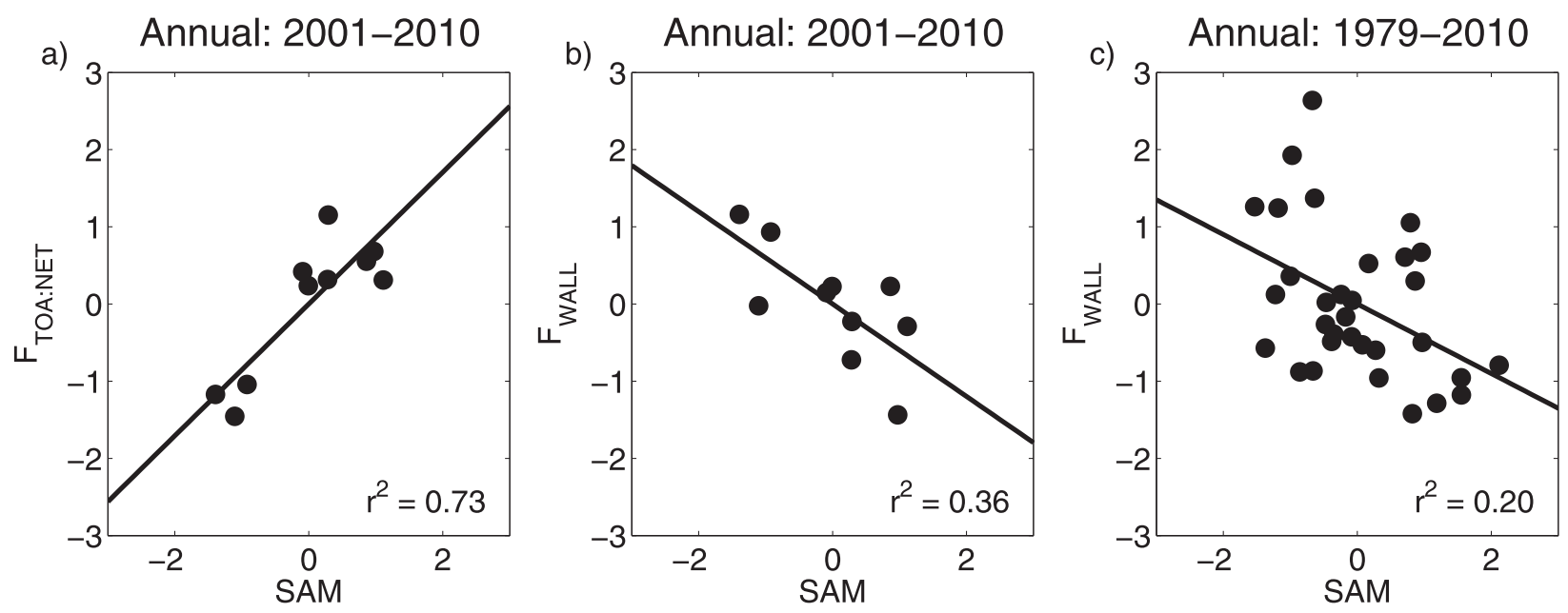

FIG. 5. As in Fig. 4, but for annual mean data.

not significant. To examine this further, we acquired monthly cloud fraction data derived from CloudSat measurements for the period June 2006-December 2010 (available from http://climserv.ipsl.polytechnique. fr/cfmip-obs/Cloudsat.html). We found a positive correlation between the SAM index and the total cloud fraction averaged over the polar cap (not shown). However, this correlation between the SAM and cloud cover is not statistically significant.

The negative SAM- $F_{\text {TOA:Sw }}$ correlation in DJF is countered by a positive SAM- $F_{\text {TOA:LW }}$ correlation, so the effect on $F_{\text {TOA:NET }}$ is not significant. In contrast, a similar correlation between the SAM and $F_{\mathrm{TOA}} \mathrm{LW}$ in JJA is evident in $F_{\text {TOA:NET }}$ because of the absence of SW radiation at high southern latitudes. During the austral winter season, the SAM accounts for $36 \%$ of the month-to-month variability $\left(r^{2}=0.36\right)$ in both $F_{\text {TOA:LW }}$ and $F_{\mathrm{TOA}: \mathrm{NET}}$ (Figs. $4 \mathrm{e}, \mathrm{f}$ ). The positive correlation between $F_{\mathrm{TOA}}$ :Lw and the SAM is consistent with reduced OLR resulting from surface and atmospheric cooling over the Antarctic polar cap during the positive phase of the SAM (e.g., Thompson et al. 2003, 2011).

The positive relationship between the SAM and $F_{\text {TOA:NET }}$ during austral winter also exists in the annual mean (Fig. 5a). Because changes in atmospheric energy storage must be small on annual and longer time scales, we expect $F_{\text {TOA:NET }}$ changes caused by the SAM to be compensated for by adjustments in other energy budget components. Given the approximate balance between $F_{\mathrm{TOA}: \mathrm{NET}}$ and $F_{\mathrm{WALL}}$ in the climatological energy budget (section 3), it is perhaps not surprising that the latter displays a significant inverse correlation with the SAM index, with correlations of $-0.71\left(r^{2}=0.36\right)$ and -0.44 $\left(r^{2}=0.20\right)$ for the periods $2001-10$ and 1979-2010, respectively (see Figs. 5b,c). The longer 1979-2010 period was included in order to assess the robustness of the SAM- $F_{\text {WALL }}$ correlation. Increases in the SAM index thus result in $F_{\text {TOA:NET }}$ increases, signifying less energy loss at the TOA, and this tends to be compensated for by less energy gain through horizontal transport (i.e., decreases in $F_{\mathrm{WALL}}$ ).

To better understand the relationship between $F_{\text {WALL }}$ and the SAM, we computed their correlation for each month, during the 2001-10 and 1979-2010 periods (Fig. 6). The correlation is negative for most months of the year, but is only statistically significant for the months of March and November (November) during 2001-10 (1979-2010).

The total horizontal energy flux convergence $F_{\text {WALL }}$ is the sum of four components, $F_{T}, F_{k}, F_{q}$, and $F_{\Phi}$, which represent the convergence of the internal, kinetic, latent, and potential energy fluxes, respectively [see Eq. (5)]. In Fig. 7, we show the regression of $F_{\mathrm{WALL}}$ and its components onto the SAM index. The regression of $F_{\Phi}$ onto the SAM index is negative, which is expected because increases in the SAM are associated with negative tendencies in geopotential height over the polar cap. In contrast, there is generally a positive relationship between the SAM and $F_{T}$, presumably reflecting increased convergence of sensible heat by transient eddies because of a poleward-shifted storm track. Regression coefficients for $F_{q}$ and $F_{k}$ are comparatively small, though it is important to note that even small changes in $F_{q}$ could be relevant for understanding observed relationships between the SAM and Antarctic snowfall (e.g., Thomas et al. 2008). Figure 7 thus indicates that the lack of a statistically significant SAM- $F_{\text {WALL }}$ correlation during most months is due to opposing effects of the SAM on the potential and internal energy flux convergence, so that changes in the total energy flux 
a) Correlation: $2001-2010$

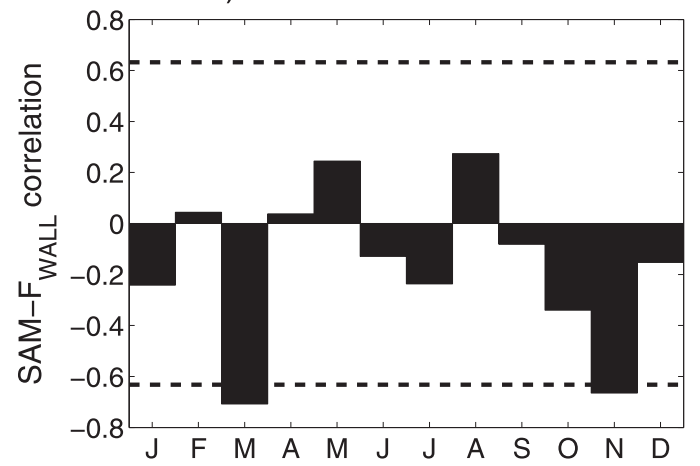

b) Correlation: $1979-2010$

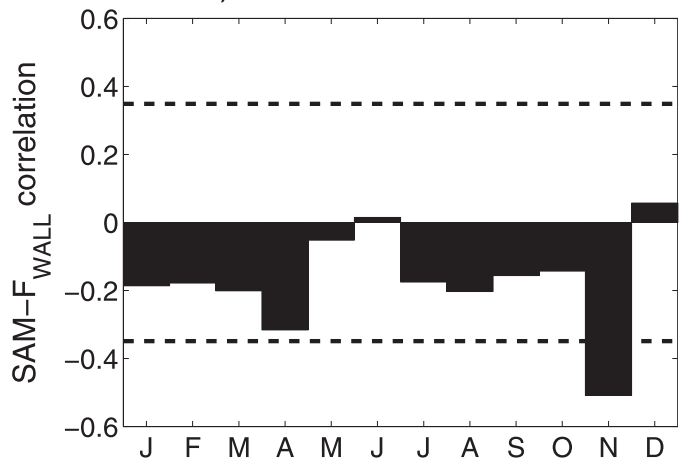

FIG. 6. Linear correlations by month between $F_{\text {WALL }}$ and the SAM index based on data for (a) 2001-10 and (b) 1979-2010. The linear trend was removed from each time series prior to computing the correlations. Dashed lines indicate the $95 \%$ significance level.

convergence are relatively modest. In November, however, this cancellation between $F_{\Phi}$ and $F_{T}$ changes breaks down (with the latter actually being slightly negative), and decreases in $F_{\Phi}$ produce statistically significant decreases in $F_{\text {WALL }}$. We note that this result still holds for November even when 2002 (the year of the major SSW) is excluded. It is not immediately clear why the relationship between the SAM and $F_{T}$ is different in November relative to the rest of the year. An intriguing possibility, however, is that this feature is in some way related to the final warming of the polar stratosphere and associated breakdown of the polar vortex that occur during austral spring.

\section{b. Links to Antarctic surface temperature variability}

Variations in Antarctic surface climate have commonly been interpreted in terms of changes in ENSO or the SAM (e.g., Turner 2004; Thompson et al. 2011). Here, we examine how these surface climate variations are tied to variations in the energy budget itself. In Fig. 8a, we show the regression of monthly mean SAT onto $F_{T}$ during DJF 2001-10. SAT data are weather station observations from READER. Regression coefficients are indicated by colored circles, with numbers denoting the percentage of the SAT variance that can be explained by $F_{T}$. Increases in $F_{T}$ are associated with an overall warming of the Antarctic Peninsula and cooling of East Antarctica. We also examined the relationship between SAT and $F_{\mathrm{WALL}}$ and found it to be generally weak (not shown). This is due to the fact that $F_{\mathrm{WALL}}$ variations during DJF tend to be relatively small because of compensation between changes in $F_{T}$ and $F_{\Phi}$ (Fig. 7)

The pattern of SAT change in Fig. 8a is similar to the one obtained from the SAM (Fig. 8b), which is not surprising because $F_{T}$ and the SAM index are positively correlated (see Fig. 7). We note, though, that at most Antarctic stations $F_{T}$ explains a greater percentage of the month-to-month variability in SAT than the SAM. Interestingly, this is only true in DJF. During the other seasons of the year, it is the SAM that is the better predictor of Antarctic SAT variability (not shown). The reasons for this seasonal difference are not immediately clear. Nevertheless, it is apparent from this analysis that the atmospheric energy budget can be a useful framework for interpreting variations in Antarctic surface climate.

\section{Summary and conclusions}

In this paper, we have presented a new estimate of the Antarctic atmospheric energy budget for the 2001-10 period. The energy budget was constructed using CERES satellite measurements for TOA radiative fluxes and ERA-Interim for all other energy budget components.

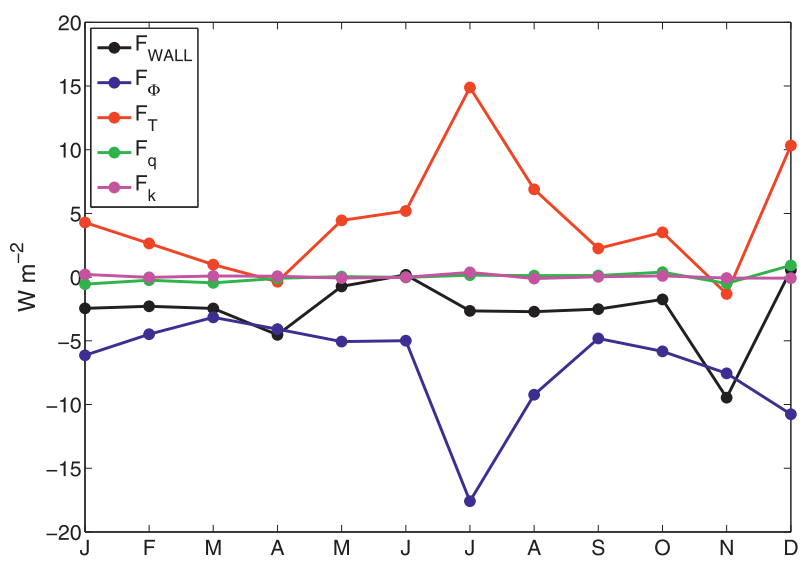

FIG. 7. Regression of $F_{\text {WALL }}$ and its components onto the SAM index. 
a) SAT regressed onto $F_{T}$ : DJF 2001-2010

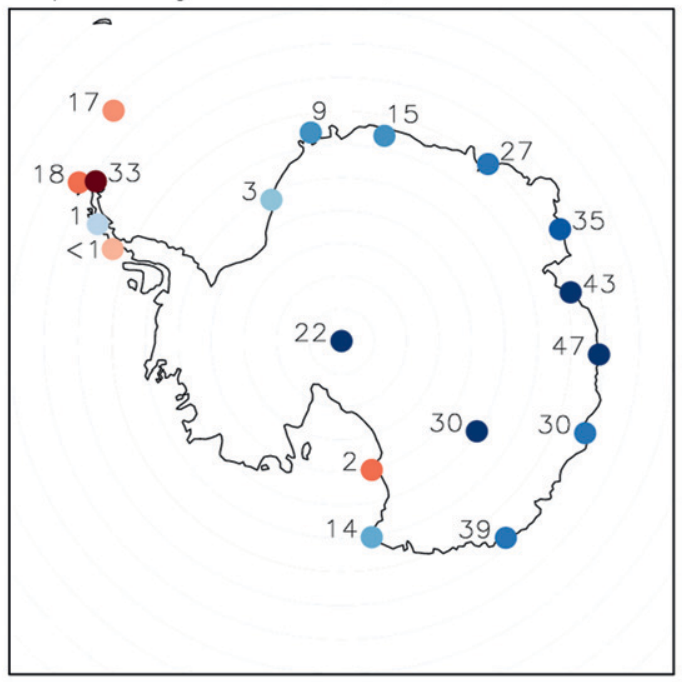

b) SAT regressed onto SAM: DJF 2001-2010

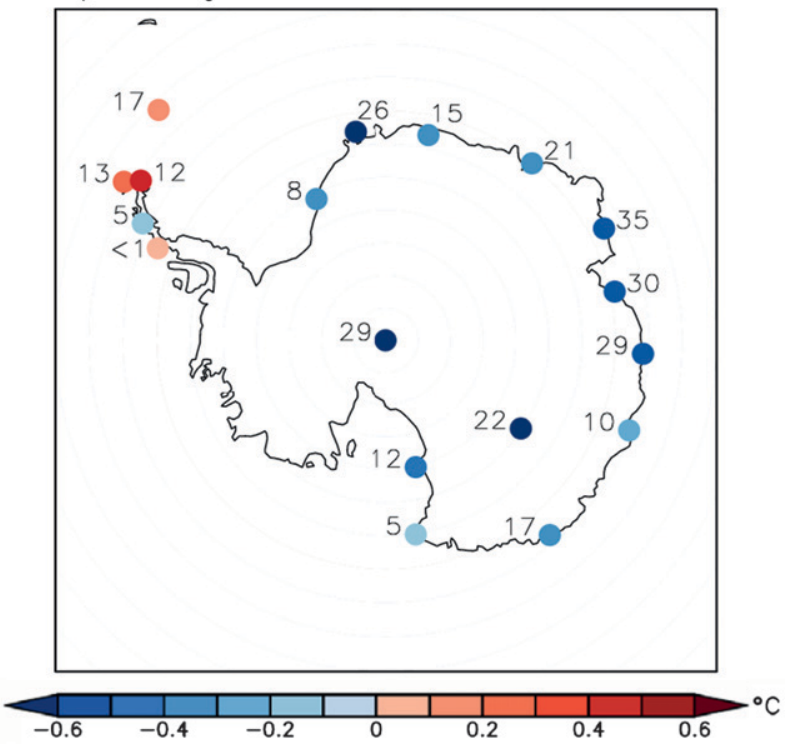

FIG. 8. (a) SAT regressed onto $F_{T}$ using monthly mean data for DJF 2001-10. Regression coefficients $\left({ }^{\circ} \mathrm{C}\right)$ are shown as colored circles, with numbers indicating the percentage of SAT variance explained. (b) As in (a), but for SAT regressed onto the SAM index.

We have focused on the climatological mean energy budget, as well as intraseasonal-to-interannual variability.

The climatological mean Antarctic energy budget is characterized by an approximate balance between the TOA net radiation and the horizontal convergence of atmospheric energy transport. This fundamentally couples TOA radiative perturbations over the Antarctic polar cap with changes in the large-scale circulation of the extratropical Southern Hemisphere. In Part II, we discuss how this is relevant for understanding the circulation response to stratospheric ozone depletion at the end of the twentieth century and ozone recovery in the twenty-first century. Another characteristic of the present-day Antarctic energy budget is a relatively small net surface energy flux throughout the year, which differentiates the Antarctic from the Arctic (e.g., Porter et al. 2010). It will be important to monitor any changes in $F_{\mathrm{SFC}: \mathrm{NET}}$ that occur in the coming decades as climate change progresses. For example, if mass loss from the Antarctic ice sheet accelerates, it will be reflected as a negative trend in the annual mean $F_{\mathrm{SFC}: \mathrm{NET}}$, indicating a larger downward net energy flux at the surface. In this regard, changes in the net surface energy flux can potentially serve as a useful diagnostic for assessing future changes in ice sheet mass balance, complementing the information provided by satellite gravity measurements, sea level change, and other methods.

Intraseasonal-to-interannual variability in the energy budget bears a strong signature of the SAM. In contrast, we find that ENSO impacts on the Antarctic mean energy budget are generally weaker, which is partly due to the cancellation of opposite-signed regional anomalies (e.g., between the Weddell and Ross Seas). The SAM is significantly correlated with $F_{\mathrm{TOA}} \mathrm{Sw}$, $F_{\mathrm{TOA}: \mathrm{LW}}, F_{\mathrm{SFC}: \mathrm{LH}+\mathrm{SH}}$, and $F_{\mathrm{SFC}: \mathrm{NET}}$ in DJF and with $F_{\mathrm{TOA}: \mathrm{LW}}$ and $F_{\mathrm{TOA}: \mathrm{NET}}$ in JJA (see Table 2 ). The positive correlation with $F_{\mathrm{TOA} \text { NET }}$ in JJA also exists in the annual mean (Fig. 5). On annual time scales, changes in atmospheric energy storage are small, and increases in $F_{\text {TOA:NET }}$ caused by the SAM are compensated for by decreases in $F_{\mathrm{WALL}}$. There is a negative SAM- $F_{\mathrm{WALL}}$ correlation during most months of the year (Fig. 6), but the correlation tends to not be statistically significant because decreases in the potential energy flux convergence are largely balanced by increases in the internal energy flux convergence. In November, however, this cancellation between $F_{\Phi}$ and $F_{T}$ changes breaks down, and the internal energy flux convergence actually decreases slightly in response to an increase in the SAM index (Fig. 7). While the reasons for this seasonal reversal in the sign of the $F_{T}$ change are not immediately clear, the timing during austral spring suggests that the final warming of the polar stratosphere and associated breakdown of the polar vortex may play a role. That stratospheric variability can be important is further implied by the strong energy budget response to the Southern Hemisphere major SSW in September 2002 (Fig. 3).

It is important to comment on a couple of issues regarding our analysis. First, we have considered only the linear relationships between ENSO/SAM and the Antarctic energy budget, thus neglecting the possibility of nonlinear interactions. Second, the discussion has been framed in such a way that the energy budget responds to variability in ENSO and the SAM. It 
should be acknowledged, however, that this relationship may work in the opposite sense as well. In other words, changes in energy budget components, either caused by ENSO/SAM or not, may also be drivers of changes in these large-scale circulation modes.

Finally, we emphasize that analyses of the atmospheric energy budget are helpful for understanding variations in surface climate. We have shown in this paper that variability in Antarctic summertime SAT is strongly tied to changes in the internal energy flux convergence over the polar cap. During the austral summer season, $F_{T}$ explains a greater percentage of the month-to-month and year-to-year SAT variability than the more widely used SAM index (Fig. 8). In Part II, we examine the links between the energy budget and multidecadal-scale Antarctic climate change driven by stratospheric ozone changes and increases in well-mixed greenhouse gases.

Acknowledgments. We thank three anonymous reviewers whose comments helped strengthen the manuscript. We gratefully acknowledge support from the NSF Antarctic Sciences program, ANT 09-44063. We thank Dennis Shea and John Fasullo for providing the CERES surface radiative fluxes.

\section{REFERENCES}

Baldwin, M. P., and T. J. Dunkerton, 1999: Downward propagation of the Arctic Oscillation from the stratosphere to the troposphere. J. Geophys. Res., 104, 30 937-30946.

_ , and —, 2001: Stratospheric harbingers of anomalous weather regimes. Science, 244, 581-584.

Berrisford, P., P. Kållberg, S. Kobayashi, D. Dee, S. Uppala, A. J. Simmons, P. Poli, and H. Sato, 2011: Atmospheric conservation properties in ERA-Interim. Quart. J. Roy. Meteor. Soc., 137, 1381-1399.

Bracegirdle, T. J., and G. J. Marshall, 2012: The reliability of Antarctic tropospheric pressure and temperature in the latest global reanalyses. J. Climate, 25, 7138-7146.

Bromwich, D. H., A. J. Monaghan, and Z. Guo, 2004: Modeling the ENSO modulation of Antarctic climate in the late 1990s with the Polar MM5. J. Climate, 17, 109-132.

_ _ J. P. Nicolas, and A. J. Monaghan, 2011: An assessment of precipitation changes over Antarctica and the Southern Ocean since 1989 in contemporary global reanalyses. J. Climate, 24, 4189-4209.

Calvo Fernández, N., R. R. García, R. García Herrera, D. Gallego Puyol, L. Gimeno Presa, E. Hernández Martín, and P. Ribera Rodríguez, 2004: Analysis of the ENSO signal in tropospheric and stratospheric temperatures observed by MSU, 1979-2000. J. Climate, 17, 3934-3946.

Comiso, J. C., and F. Nishio, 2008: Trends in the sea ice cover using enhanced and compatible AMSR-E, SSM/I, and SMMR data. J. Geophys. Res., 113, C02S07, doi:10.1029/2007JC004257.

Connolley, W. M., 1996: The Antarctic temperature inversion. Int. J. Climatol., 16, 1333-1342.

Cullather, R. I., and M. G. Bosilovich, 2012: The energy budget of the polar atmosphere in MERRA. J. Climate, 25, 5-24.
Dee, D. P., and Coauthors, 2011: The ERA-Interim reanalysis: Configuration and performance of the data assimilation system. Quart. J. Roy. Meteor. Soc., 137, 553-597.

Domack, E., and Coauthors, 2005: Stability of the Larsen B ice shelf on the Antarctic Peninsula during the Holocene epoch. Nature, 436, 681-685.

Genthon, C., and G. Krinner, 1998: Convergence and disposal of energy and moisture on the Antarctic polar cap from ECMWF reanalyses and forecasts. J. Climate, 11, 1703-1716.

Kalnay, E., and Coauthors, 1996: The NCEP/NCAR 40-Year Reanalysis Project. Bull. Amer. Meteor. Soc., 77, 437-471.

Kaplan, A., M. Cane, Y. Kushnir, A. Clement, M. Blumenthal, and B. Rajagopalan, 1998: Analyses of global sea surface temperature 1856-1991. J. Geophys. Res., 103, 18567-18589.

Le Quéré, C., and Coauthors, 2007: Saturation of the Southern Ocean $\mathrm{CO}_{2}$ sink due to recent climate change. Science, 316, $1735-1738$.

Liu, J., J. A. Curry, and D. G. Martinson, 2004: Interpretation of recent Antarctic sea ice variability. Geophys. Res. Lett., 31, L02205, doi:10.1029/2003GL018732.

Loeb, N. G., B. A. Wielicki, D. R. Doelling, G. L. Smith, D. F. Keyes, S. Kato, N. Manalo-Smith, and T. Wong, 2009: Toward optimal closure of the earth's top-of-atmosphere radiation budget. J. Climate, 22, 748-766.

Marshall, G. J., 2003: Trends in the southern annular mode from observations and reanalyses. J. Climate, 16, 4134-4143.

Mayewski, P. A., and Coauthors, 2009: State of the Antarctic and Southern Ocean climate system. Rev. Geophys., 47, RG1003, doi:10.1029/2007RG000231.

Nakamura, N., and A. H. Oort, 1988: Atmospheric heat budgets of the polar regions. J. Geophys. Res., 93, 9510-9524.

Okada, I., and T. Yamanouchi, 2002: Seasonal change of the atmospheric heat budget over the Southern Ocean from ECMWF and ERBE data. J. Climate, 15, 2527-2536.

Orsolini, Y. J., C. E. Randall, G. L. Manney, and D. R. Allen, 2005: An observational study of the final breakdown of the Southern Hemisphere stratospheric vortex in 2002. J. Atmos. Sci., 62, 735-747.

Porter, D. F., J. J. Cassano, M. C. Serreze, and D. N. Kindig, 2010: New estimates of the large-scale Arctic atmospheric energy budget. J. Geophys. Res., 115, D08108, doi:10.1029/2009JD012653.

Purkey, S. G., and G. C. Johnson, 2012: Global contraction of Antarctic Bottom Water between the 1980s and 2000s. J. Climate, 25, 5830-5844.

Rignot, E., 2011: Is Antarctica melting? Wiley Interdiscip. Rev. Climate Change, 2, 324-331.

Smith, K. L., M. Previdi, and L. M. Polvani, 2013: The Antarctic atmospheric energy budget. Part II: The effect of ozone depletion and its projected recovery. J. Climate, in press.

Smith, S. R., and C. R. Stearns, 1993: Antarctic pressure and temperature anomalies surrounding the minimum in the Southern Oscillation index. J. Geophys. Res., 98, 13071-13083.

Steig, E. J., D. P. Schneider, S. D. Rutherford, M. E. Mann, J. C. Comiso, and D. T. Shindell, 2009: Warming of the Antarctic ice-sheet surface since the 1957 International Geophysical Year. Nature, 457, 459-462.

Thomas, E. R., G. J. Marshall, and J. R. McConnell, 2008: A doubling in snow accumulation in the western Antarctic Peninsula since 1850. Geophys. Res. Lett., 35, L01706, doi:10.1029/2007GL032529.

Thompson, D. W. J., and J. M. Wallace, 2000: Annular modes in the extratropical circulation. Part I: Month-to-month variability. J. Climate, 13, 1000-1016. 
S. Lee, and M. P. Baldwin, 2003: Atmospheric processes governing the Northern Hemisphere annular mode/North Atlantic Oscillation. The North Atlantic Oscillation: Climatic Significance and Environmental Impact, Geophys. Monogr., Vol. 134, Amer. Geophys. Union, 81-112.

- M. P. Baldwin, and S. Solomon, 2005: Stratospheretroposphere coupling in the Southern Hemisphere. J. Atmos. Sci., 62, 708-715.

— S. Solomon, P. J. Kushner, M. H. England, K. M. Grise, and D. J. Karoly, 2011: Signatures of the Antarctic ozone hole in Southern Hemisphere surface climate change. Nat. Geosci., 4, 741-749.

Trenberth, K. E., 1991: Climate diagnostics from global analyses: Conservation of mass in ECMWF analyses. J. Climate, 4, 707722.

_ 1997: Using atmospheric budgets as a constraint on surface fluxes. J. Climate, 10, 2796-2809.

— first-century energy budgets of the southern oceans. J. Climate, 23, 440-454.

, and Coauthors, 2007: Observations: Surface and atmospheric climate change. Climate Change 2007: The Physical Science Basis, S. Solomon et al., Eds., Cambridge University Press, 235-336.
_ J. T. Fasullo, and J. Kiehl, 2009: Earth's global energy budget. Bull. Amer. Meteor. Soc., 90, 311-323.

Turner, J., 2004: The El Niño-Southern Oscillation and Antarctica. Int. J. Climatol., 24, 1-31.

— , and Coauthors, 2004: The SCAR READER project: Toward a high-quality database of mean Antarctic meteorological observations. J. Climate, 17, 2890-2898.

- and Coauthors, 2005: Antarctic climate change during the last 50 years. Int. J. Climatol., 25, 279-294.

_ - and Coauthors, 2009: Non-annular atmospheric circulation change induced by stratospheric ozone depletion and its role in the recent increase of Antarctic sea ice extent. Geophys. Res. Lett., 36, L08502, doi:10.1029/2009GL037524.

van de Berg, W. J., M. R. van den Broeke, and E. van Meijgaard, 2007: Heat budget of the East Antarctic lower atmosphere derived from a regional atmospheric climate model. J. Geophys. Res., 112, D23101, doi:10.1029/2007JD008613.

Wielicki, B. A., B. R. Barkstrom, E. F. Harrison, R. B. Lee, G. L. Smith, and J. E. Cooper, 1996: Clouds and the Earth's Radiant Energy System (CERES): An Earth Observing System experiment. Bull. Amer. Meteor. Soc., 77, 853-868.

Zwally, H. J., J. C. Comiso, C. L. Parkinson, D. J. Cavalieri, and P. Gloersen, 2002: Variability of Antarctic sea ice 1979-1998. J. Geophys. Res., 107, 3041, doi:10.1029/2000JC000733. 